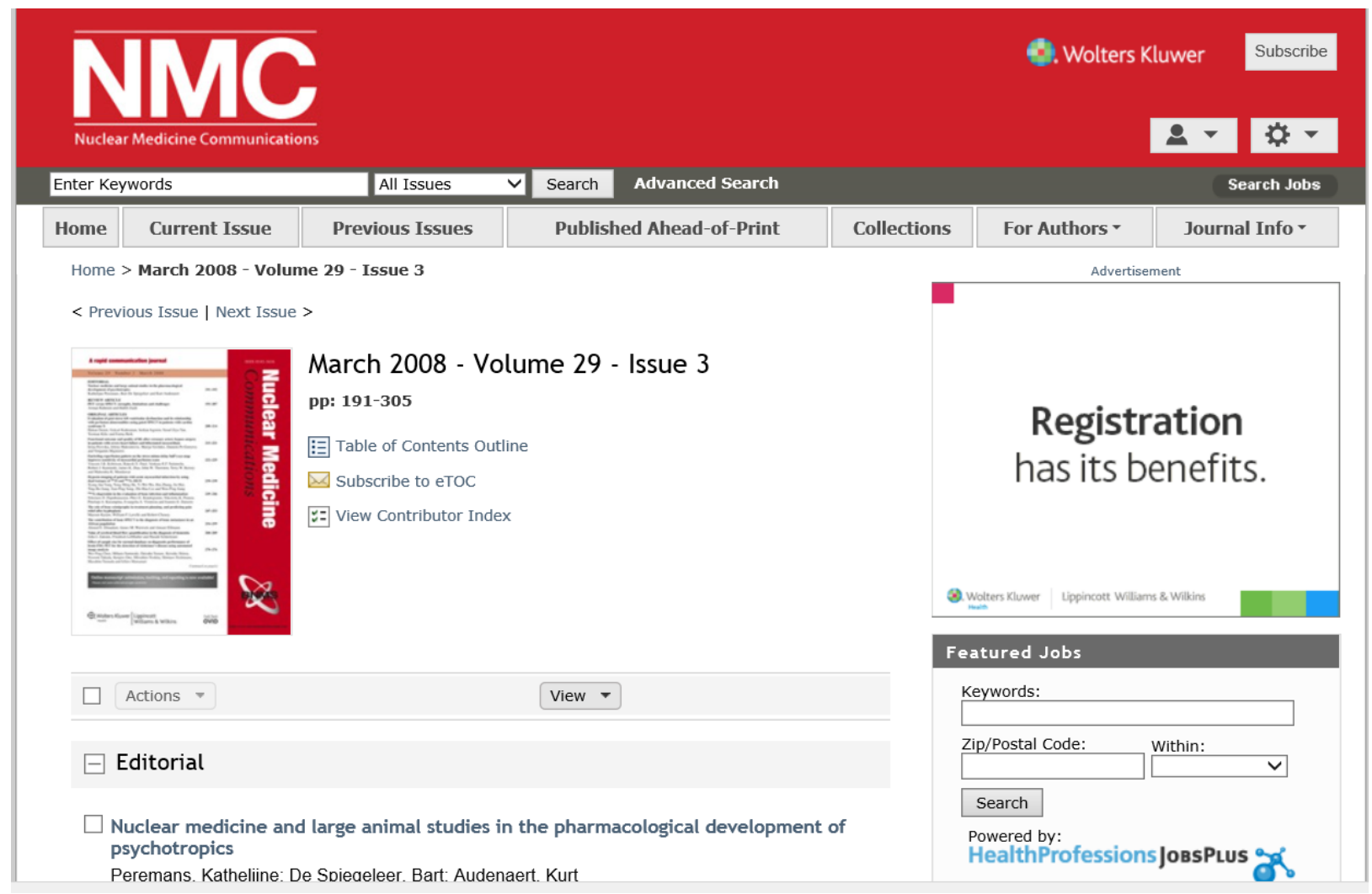

Peovska, Irena; Maksimovic, Jelena; Vavlukis, Marija; Po Gorceva, Daniela; Majstorov, Venjamin Functional outcome and quality of life after coronary artery bypass surgery in patients with severe heart failure and hibernated myocardium. Nuclear Medicine Communications:

March 2008 - Volume 29 - Issue 3 - pp 215-221

doi: 10.1097/MNM.0b013e3282f3add9

ISSN 0143-3636

Online ISSN 1473-5628

http://journals.Iww.com/nuclearmedicinecomm/pages/contributorindex.aspx?filter=P\&year=2 $\underline{008 \& \text { issue }=03000}$

\title{
IF 1.669
}

\section{Abstract:}

Background: Myocardial viability is an important parameter, predictive of improvement in left ventricular function after coronary artery bypass surgery (CABG). We wanted to define the relationship between the extent of hibernated myocardium and improvement in ejection fraction function and quality of life after CABG.

Methods: Sixty-five consecutive patients with ischaemic cardiomyopathy (mean LVEF $<40 \%$ ) undergoing surgical revascularization were studied with $99 \mathrm{mTc}$-sestamibi myocardial perfusion Gated SPECT imaging (MPI) to assess preoperative myocardial viability. Patients were divided into two groups, based on the extent of viable myocardium before CABG: group 1, 39 patients with more than four viable segments; and group 2, 26 patients with fewer than four viable segments. Regional and global ejection fraction function, heart failure symptoms and quality of life were measured before and $14 \pm 4$ months after 
revascularization. We used bull's eye quantitative analysis of MPI scans and a 17-segment model of ejection fraction function and perfusion evaluation.

Results: The number of viable segments per patient was directly related to the improvement in LVEF after revascularization $(r=0.79, P<0.01)$. Patients with more than four viable segments representing $24 \%$ of the left ventricle yielded the sensitivity of $83 \%$ and specificity of $79 \%$, respectively, for predicting improvement in LVEF. Furthermore, the presence of four or more viable segments predicted improvement in heart failure symptoms and quality of life after revascularization.

Conclusion: The presence of more than four viable segments (24\% of the left ventricle) on MPI in patients with ischaemic heart failure before CABG surgery is significantly correlated with the improvement in LVEF, heart failure symptoms and quality of life post-operatively. 